Corrigendum to Volume 114, Number 5, pp. 802-810

Published online: 18 September 2009

(C) Springer-Verlag 2009

\title{
Radiological features of complications of laparoscopic adjustable gastric banding
}

Caratteristiche radiologiche delle complicanze del bendaggio gastrico per via laparoscopica

\section{T. Moey • W.C.G. Peh • M.J. Clarke • N. Dubey • A. Cheng}

In the online version of the article unfortunately authors' names were misspelled.

The original version of the article can be found at:

http://dx.doi.org/10.1007/s11547-009-0389-3 